\title{
A BUSCA DA QUALIDADE NA EDUCAÇÃO SUPERIOR A DISTÂNCIA NO BRASIL SITUAÇÃO ATUAL E ALGUMAS REFLEXÕES
}

\section{(THE SEARCH FOR QUALITY IN HIGHER DISTANCE EDUCATION IN BRAZIL CURRENT SITUATION AND SOME REFLECTIONS)}

Marlene M. Blois

CREAD, UNICARIOCA/UNIVIR (Brasil)

\section{RESUMEN}

Panorama da Educação no Brasil, com destaque para a Educação Superior. Número de alunos matriculados e formação dos docentes no ensino superior. Causas do crescimento da Educação a Distância no país e instituições de Educação Superior credenciadas para ofertas de EAD. Definição para a EAD.

A Regulamentação e os Referenciais de Qualidade para a EAD. A legislação em vigor no país. A avaliação de programas e cursos de EAD. Diplomas de cursos realizados em instituições estrangeiras. Os critérios de qualidade recomendados pelo Ministério da Educação para a EAD. Pontos para reflexão sobre os temas abordados.

\section{ABSTRACT}

Overview of the Education Sector in Brazil, with focus on Higher Education. Number of enrolled students and the teachers' formation in Higher Education. Causes of the growth of Distance Education $(\mathrm{EAD})$ the in the country and institutions of Higher Education accredited for offers of EAD. Definition of EAD.

The Regulation and the Indicators of Quality for EAD. The brazilian legislation of EAD. The evaluation of programs and courses of EAD. Diplomas of courses accomplished in foreign institutions. The quality criteria recommended by the Ministry of Education for EAD. Points for reflection on the approached themes. 


\section{APRESENTAÇÃO}

A Educação Superior no Brasil e sua vinculação com a EAD são os pontos de partida e pano de fundo deste artigo, dando destaque à incorporação das novas tecnologias aos cursos superiores oferecidos. A legislação em vigor no país, questões referentes à qualidade e aos critérios de qualidade recomendados pelo Ministério da Educação são analisados para, finalmente, levantar pontos para reflexão sobre o tema.

\section{A EDUCAÇÃO NO BRASIL E A EAD}

Um dos grandes desafios enfrentados pela sociedade brasileira, que remonta ao tempo em que era colônia portuguesa e antecede à sua independência ( 1822), está no acesso da população à Educação, em seus diferentes níveis e modalidades. Atender a todos que dela necessitam com qualidade, segue sendo uma utopia com a mesma idade que o país, ou seja, desde o seu descobrimento em 1500. Ao longo do tempo, mais do que garantir o direito constitucional à Educação, é preciso manter um enorme contingente de alunos nas classes, tendo à frente professores com formação pedagógica e com perspectivas de atualização constante. Vale lembrar que uma exigência legal - ter o ano de 2007 como prazo para que todos os professores das classes iniciais do Ensino Fundamental tenham habilitação em nível superior para o magistério - não será alcançada, embora a Educação a Distância venha dando uma grande contribuição nesse sentido.

O mundo do trabalho é outro ponto crítico a demandar um enorme esforço, tanto dos governos, quanto de órgãos de classe e das próprias organizações, para atender a necessidade premente de preparação de pessoal, que responda, nos postos de trabalho, às exigências de um mercado cada vez mais competitivo em todos os aspectos. Poder contar com pessoal que possa dar respostas rápidas às mudanças cotidianas, refletir sobre essas mudanças, saber interagir com as novas tecnologias, fazendo delas um diferencial a seu favor e a favor da organização, é o que as empresas procuram nos colaboradores já contratados e a contratar. A necessidade cada vez maior de tornar a Educação Continuada um componente da cultura incorporada em cada profissional, fez surgir o que denomino de "empresa-escola", ou seja, a que toma para si, também, o processo de capacitar e atualizar os colaboradores para o seu negócio e, portanto, para o mercado, valorizando o capital intelectual da empresa e a criatividade de cada um. Nesse caso, estão tanto as grandes empresas, que criam suas universidades corporativas, quanto as de médio e pequeno porte, que treinam seus funcionários "em serviço" , sem contar com a mesma estrutura. Dessa maneira, não deixam de acompanhar os avanços tecnológicos que impactam o seu próprio negócio. Como são mais ágeis na tomada de decisão do que as nossas escolas formais, especialmente as universidades, buscam não perder espaços no mercado globalizado, investindo em seus recursos humanos.

No caso da educação fundamental, se sua universalização está estatisticamente atingida (cerca de 95 por cento na faixa de 7 a 14 anos), o país viu seus jovens se mo- 
vimentarem para dar seqüência aos estudos e buscar o Ensino Médio. No entanto, apenas 35\% dos jovens entre 15 e 17 anos se encontram aí matriculados, conseqüência, por certo, de não se ter seguido com o modelo anterior de ensino profissional, que os mantinha na escola, exercendo forte apelo aos jovens, notadamente os que não aspiravam chegar à Universidade, mas não descartavam, em definitivo, o sonho de "ser alguém" pelo caminho da Educação, e lutar por uma vaga no ensino superior.

O número total de matrículas nas várias modalidades de ensino no Brasil, de acordo com censos do INEP (2004), da educação infantil (creche e pré-escola), nível fun-

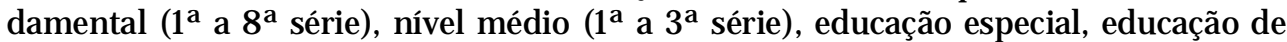
jovens e adultos, nível técnico e abrangendo, também, a educação superior, totalizava 59.704.022 estudantes. (Informativo no 119 do Instituto Nacional de Estudos e Pesquisas Educacionais Anísio Teixeira - Inep). Estados e municípios brasileiros respondem por mais de $80 \%$ do total das matrículas.

Quanto à Universidade Brasileira, embora não apresentando a mesma longa história de muitas de suas congêneres latino-americanas, nas quatro últimas décadas apresentou uma expansão pouco vista em outros países com desenvolvimento similar, mesmo no continente. O país conta com o Sistema Nacional de Educação Superior, conjunto formado pelo conjunto das instituições federais de educação superior e pelas instituições privadas. À União cabe manter as instituições federais públicas, além de regular o funcionamento das instituições privadas, de forma a garantir a qualidade da educação. Na estrutura do Ministério da Educação, compete à Secretaria de Educação Superior compete planejar, orientar, coordenar e supervisionar o processo de formulação e implementação da política nacional de educação superior. Não fazem parte do Sistema as instituições estaduais e municipais.

Em 2003, o país possuía 3.900.000 estudantes, em 16.453 cursos de graduação, com crescimento de 11,7 por cento em relação ao ano anterior, tendo as 207 instituições públicas respondido por 7,8 por cento e as 1.652 particulares, por 18 por cento desse aumento. Vale destacar que, em 2002, o número de vagas oferecidas nas instituições de ensino superior, pela primeira vez, ultrapassou o de concluintes do ensino médio regular, sendo de 12,9 por cento o crescimento total da oferta de vagas.

Tabla 1. Número de instituições de educação superior, cursos e matrículas por categoria administrativa - Brasil - 1998 - 2003

\begin{tabular}{|c|c|c|c|c|c|c|c|c|c|}
\hline & \multicolumn{3}{|c|}{ Instituições } & \multicolumn{3}{|c|}{ Cursos } & \multicolumn{3}{|c|}{ Matrículas } \\
\hline Ano & Total & Pública & Privada & Total & Pública & Privada & Total & Pública & Privada \\
\hline 1998 & 973 & 209 & 764 & 6.950 & 2.970 & 3.980 & 2.125 .958 & 804.729 & 1321.229 \\
\hline 1999 & 1097 & 192 & 905 & 8.878 & 3.494 & 5.384 & 2.369 .945 & 832.022 & 1537.923 \\
\hline 2000 & 1.180 & 176 & 1004 & 10.585 & 4.021 & 6.564 & 2.694 .245 & 887.026 & 1807.219 \\
\hline 2001 & 1.391 & 183 & 1208 & 12. 155 & 4.401 & 7.754 & 3.030 .754 & 939.225 & 2.091529 \\
\hline 2002 & 1637 & 195 & 1442 & 14.399 & 5.252 & 9.147 & 3.479.913 & 1051.655 & 2.428 .258 \\
\hline 2003 & 1.859 & 207 & 1652 & 16.453 & 5.662 & 10.791 & 3.887 .771 & 1.137 .119 & 2.750 .652 \\
\hline
\end{tabular}
Fonte: Inep/MEC. 
Vale observar, ainda segundo dados atuais do Censo da Educação Superior, que o ritmo de crescimento das IES privadas está diminuindo, enquanto nas públicas permanece estável. Desde 2000, caiu de 20,3\% ao ano para 8,3\%, em 2004.

Quanto às funções docentes, estavam em exercício nas instituições brasileiras, em 2003, 254.153 profissionais, sendo nas públicas 88.795 (39,5 por cento doutores e 27,3 por cento, mestres) e, nas instituições privadas, 165.358 (com doutorado, 11,8 por cento, e com mestrado, 39,4 por cento).

No entanto, a desigualdade no atendimento a população que deseja cursar uma instituição de ensino superior pode ser constatada, quando se comprova que apenas 20 dos cerca de 5.600 municípios brasileiros concentram 45 por cento do total de alunos, ou seja, 1.578.222. Duas das nossas cidades - São Paulo e Rio de J aneiro - detêm, respectivamente, 377.471 (10,8 por cento) e 236.644 (6,8 por cento) do total dos estudantes. (Censo de Educação Superior 2003, MEC/ INEP).

Para fazer frente às desigualdades de acesso ao ensino superior, o país traçou, há cerca de seis anos, metas ambiciosas para levar 40 por cento dos jovens brasileiros, entre 18 e 24 anos, à universidade, definidas no Plano Nacional de Educação, para o decênio 2000-2010. No entanto esse índice está longe de ser alcançado pelas vias tradicionais de ofertas educativas, abrindo espaço para que a EAD possa fortemente contribuir para o alcance da meta estabelecida.

Pesquisa realizada, em 2004, por duas organizações não governamentais (o Instituto Monitor e a ABED/Associação Brasileira de Educação a Distância), sobre a realidade da EAD no Brasil, destaca que 1.100.000 estudantes realizaram algum curso a distância, em instituição credenciada oficialmente, seja no Ensino Superior, Médio ou Fundamental, e em seis outras grandes organizações , a saber: a Fundação Roberto Marinho, que oferece o Telecurso 2.000 para jovens e adultos; o SEBRAE , com seus cursos voltados para o segmento que atua em micro e pequenas empresas; o Governo do Estado de São Paulo, prioritariamente com projetos para profissionais da Educação; a Telemar, empresa do ramo das telecomunicações, que atua através da sua universidade corporativa, a UNITE, com cursos a seus colaboradores; o Serviço Nacional de Aprendizagem Industrial (SENAI) e o Serviço Nacional de Aprendizagem Comercial (SENAC), com cursos para profissionais da indústria e do comércio/ prestação de serviços, respectivamente.

Outro ponto levantado na pesquisa diz respeito às instituições credenciadas nos Estados e Municípios, que atuam nos ensinos fundamental, médio e profissionalizante, e atendem a jovens e adultos supletivamente. Elas são responsáveis por atender 48,6 por cento do universo de estudantes de $\mathrm{EAD}$, que representa mais de 150.000 alunos. Vale destacar que este número se aproxima dos 160.000 que estão matriculados em cursos superiores de graduação, seqüencial ou de pós-graduação.

Em outro estudo, o Instituto de Pesquisas Avançadas em Educação (Rio de Janeiro/ Brasil), a partir dos pareceres do Conselho Nacional de Educação e Portarias do Ministério da Educação, levantou, no período de 1998-2005, 128 instituições de 
Ensino Superior credenciadas para programas de EAD. Excluindo o ano de 1999, quando não se apresenta nenhuma instituição, a ocorrência de credenciamento assim se apresenta: em 1998, 2; em 2000, 4; no primeiro ano do novo século, 8; no ano seguinte, 34; em 2003, 25; 33 no ano de 2004 e até agosto de 2005, 22.

As pesquisas constatam o que especialistas de EAD já supunham: a EAD é a modalidade que apresenta maior crescimento nos últimos anos no país. Em se tratando de graduação e pós-graduação, comparando-se com dados levantados anteriormente pelo Ministério da Educação, o número de estudantes saltou de 76.769 para cerca de 159.366, o que confere à EAD, em apenas um ano, uma expansão de aproximadamente 100 por cento (Anuário Brasileiro Estatístico de Educação Aberta e a Distância do MEC). Em nossa opinião, esse crescimento debe-se entre outros, a fatores como: mudança de visão e valorização da $\mathrm{EAD}$, como forma de socializar o acesso ao ensino superior; ampliação do número de cursos oferecidos, que nos últimos quatro anos cresceu $600 \%$; necessidade crescente de atualização dos trabalhadores do país. Se, em 2001, os cursos à distância eram apenas 11 e, em 2002, 19, um ano depois já totalizavam 34, para, em 2004, ver a oferta atingir 77 cursos.

Outro dado a incentivar o avanço da EAD com certeza é o aumento de computadores por escola, em todos os países e a indicação de que $27 \%$ dos alunos brasileiros usam seus computadores para trabalhos escolares (número semelhante no México).

Pela legislação brasileira, atos de credenciamento para ofertas de programas de ensino superior de Educação a Distância são exclusivos da União, cabendo ao Ministério da Educação expedir documentos legais que concedem o direito de funcionamento desses programas. As Secretarias de Educação dos Estados são responsáveis pela autorização voltadas para jovens e adultos (antigo supletivo) e cursos técnicos.

A EAD no Brasil guarda características bastante interessantes, tanto com relação à natureza das organizações que disponibilizam cursos, em termos de suas vinculações administrativas (públicas - federal, estadual, municipal - e privadas), como o nível do ensino oferecido (supletivo, regular; fundamental, médio, superior, profissionalizante, de extensão) e os meios ou suportes escolhidos, além de divergirem na modelagem e duração desses cursos. As chamadas gerações da EAD convivem nesse país continental, que tanto necessita de ofertas educativas de qualidade, para atender a demanda de suas carências, chegando até onde estão os que necessitam de estudar e construir novos conhecimentos.

Assim, têm-se hoje cursos de alta qualidade oferecidos on-line ou por CD-ROM, vídeo e teleconferência, como utilizando tecnologias mais tradicionais, como o material impresso, associado ou não a outros meios, como a Tv, o que caracteriza uma verdadeira convergência de meios a favor da educação. 
O crescimento, expansão e barateamento do acesso às novas tecnologias fez com que organizações até então afastadas da EAD passassem a encará-la como um desafio a ser vencido, prevendo, em curto prazo incorporá-la às suas ações. Nesse caso está o mundo universitário em geral, que há cerca de cinco ou seis anos atrás, via a EAD como oferta exclusiva para levar ensino regular (cursos supletivos) à massa fora da faixa etária, com raras e honrosas exceções. Nesse caso está a Universidade Federal do Mato Grosso que, a partir de 1994, passa a desenvolver programas para professores das classes iniciais do ensino fundamental das escolas públicas de Mato Grosso, em parceria com secretarias de educação dos municípios do estado, culminando, a partir de 1999, com a oferta de curso de licenciatura para esse público.

Em ofertas de extensão universitária, vale o destaque para a pioneira UNICARIOCA, com a criação da UNIVIR, que caminha em 2006 para o décimo primeiro ano de ofertas on-line, principalmente focando suas ações para o mundo corporativo. Cria também uma proposta pedagógica bastante avançada, com a inclusão de tecnologia em seus cursos presenciais.

No entanto, as negociações para propostas de redes só começam no final do século passado, tomando corpo e forma a partir de 2000/2001, congregando organizações públicas estaduais, regionais e nacionais, e, separadamente, em consórcio as particulares, para a criação e oferta de cursos à distância, o que configura mudança de paradigmas e a abertura de novos papéis e possibilidades para a educação superior no Brasil.

Em 2005, o Ministério da Educação cria o Projeto Universidade Aberta do Brasil - UAB, no âmbito do Fórum das Universidades Estatais pela Educação, para a articulação e integração de um sistema nacional de educação superior a distância. Com caráter experimental, seu propósito é sistematizar as ações, programas, projetos e atividades pertencentes às políticas públicas voltadas para a ampliação e interiorização da oferta do ensino superior gratuito e de qualidade no Brasil. É uma parceria entre consórcios públicos, nos três níveis governamentais (federal, estadual e municipal), para a participação das universidades publicas e demais organizações interessadas. Não se trata, portanto, de uma nova instituição de ensino, mas de articular as já existentes, com a proposta de socializar oportunidades de ensino superior público de qualidade aos Municípios brasileiros, sem oferta ou cujos cursos ofertados não são suficientes para atender a todos os cidadãos.

Com apoio do MEC, estão sendo abertas 18.000 vagas em cursos de formação de professores a distância em universidades públicas. Há recurso para atingir pelo menos 30.000 vagas em 2006. Pela UAB, o curso escolhido para dar início às suas atividades é o de Administração, com 2.000 vagas iniciais. Em 20 de dezembro de 2005, através da Secretaria de Educação a Distancia - SEED - a UAB lançou o Edital $\mathrm{N}^{\circ} 1$, com a chamada pública para a seleção de pólos municipais de apoio presencial e de cursos superiores de Instituições Federais de Ensino Superior, na modalidade à distância. 


\section{A REGULAMENTAÇÃO E OS REFERENCIAIS DE QUALIDADE PARA A EAD}

\section{A Legislação}

Para a EAD no Brasil, o ano de 1996 constitui-se num marco, que lhe dá legitimidade e visibilidade. A lei maior da Educação no país - a Lei de Diretrizes e Bases, de n⿳0 9394, em seu artigo 80, refere-se à EAD e ao papel do Poder Público, nesses termos:

“O Poder Público incentivará o desenvolvimento e a veiculação de programas de ensino a distância em todos os níveis e modalidades de ensino e de educação continuada".

Textos legais subseqüentes tratam da regulamentação e normatizam a EAD, em alguns pontos, indicando questões como a qualidade e a avaliação. Para efeito desse trabalho estão destacados os seguintes quesitos:

- $\quad$ programas e cursos a distância no âmbito da educação superior,devem atender aos padrões nacionais de qualidade de cursos;

- Plano de Desenvolvimento Institucional - PDI deve pautar-se pelas diretrizes curriculares e pelos padrões de qualidade de cursos nacionais e integração da educação à distância ao projeto pedagógico de oferta de seus cursos superiores;

- $\quad$ cursos superiores a distância, no sistema federal de ensino, exigem a realização de verificação e avaliação prévia por especialistas designados pelo Ministério da Educação;

- autorização e o reconhecimento dos programas e cursos superiores a distância serão limitados a cinco anos, podendo ser renovados após avaliação favorável, sendo que o reconhecimento de cursos de graduação e seqüenciais a distância requererá prévia avaliação do MEC;

- $\quad$ avaliações obedecerão a procedimentos, critérios, indicadores de qualidade definidos;

- $\quad$ autorização e reconhecimento de programas a distância de mestrado e doutorado será objeto de avaliação prévia pelo Ministério;

- $\quad$ diplomas de cursos superiores de graduação a distância emitidos por instituições estrangeiras, mesmo quando realizados em cooperação com instituições sediadas no Brasil, para gerarem efeitos legais, deverão ser revalidados por universidades públicas brasileiras;

- avaliação do rendimento do aluno para fins de promoção, certificação ou diplomação, dar-se-á no processo com a realização, em algum momento, de exames presenciais;

- $\quad$ resultado das avaliações institucionais e das verificações realizadas para fins de autorização ou reconhecimento será divulgado pelo Ministério da Educação. 
Na verdade, os textos legais não chegaram a explicitar os padrões de qualidade. Em 1998, foi publicado na página da SEED/ Secretaria de Educação a Distância do MEC, o texto escrito em 1997 e publicado na revista Tecnologia Educacional $\mathrm{n}^{\circ}$ 144/98, da Associação Brasileira de Tecnologia Educacional- ABT, de autoria da Professora Carmen Moreira de Castro Neves, Diretora de Política de Educação a Distância (um documento de estudos), que especificou dez itens básicos como os indicadores de qualidade de cursos de graduação a distância.

O documento passou a servir como referência para as comissões que analisavam processos de autorização de cursos de graduação a distância. Em 2002, uma Comissão de Especialistas nomeada pela Secretaria de Educação Superior baseou-se neste documento para elaborar o Capítulo 2 de seu Relatório, que hoje servem como indicadores de qualidade.

\section{A nova Legislação em vigor}

Com a evolução crescente da EAD em todos os segmentos educacionais, um novo decreto de $\mathrm{n}$ - 5.622 foi elaborado, adotando-se um processo contínuo (desde 2003) e participativo, no qual colaboraram: Secretarias e órgãos do MEC, o Conselho Nacional de Educação, os Conselhos Estaduais de Educação, Instituições de Ensino, Associações envolvidas com a EAD e a sociedade em geral. No final de agosto de 2005, o documento foi encaminhado à Casa Civil, entrando em vigor em 19.12.2005.

A seguir, alguns destaques para efeito da temática deste estudo:

- Definição de EAD

Segundo o Decreto 5.622, de 19.12.2005 (que revoga o Decreto 2.494/98), a Educação a Distância é a modalidade educacional na qual a mediação didáticopedagógica nos processos de ensino e aprendizagem ocorre com a utilização de meios e tecnologias de informação e comunicação, com estudantes e professores desenvolvendo atividades educativas em lugares ou tempos diversos.

- Credenciamento

Na solicitação de credenciamento pela instituição interessada em oferecer curso a distancia precisa comprovar sua capacidade em oferecer tais cursos.

O parecer do Conselho Nacional de Educação, homologado pelo Ministro da Educação por meio de Portaria publicada no Diário Oficial, pode ser encontrado nos termos da Lei 9.394/96 (LDB), do Decreto 5.622 e da Portaria MEC No. 4.361/2004 (que revoga a Portaria MEC No 301/98). Pode ser consultada, também, a Portaria MEC No. 4.059/ 04 (que trata da oferta de 20\% da carga horária dos cursos superiores na modalidade semi-presencial).

- Alinhamento dos cursos e programas a distância com: 
- os fins, princípios e objetivos da educação nacional;

- as Diretrizes Curriculares Nacionais estabelecidas pelo Ministério da Educação para os respectivos níveis e modalidades educacionais

- os Referenciais de Qualidade para Educação a Distância, definido pelo Ministério da Educação, os quais terão por objetivo o desenvolvimento e a avaliação dos processos de ensino e aprendizagem;

- bibliotecas adequadas, inclusive com acervo eletrônico remoto e acesso por meio de redes de comunicação e sistemas de informação, com regime de funcionamento e atendimento aos estudantes de educação a distância.

Os resultados das avaliações mencionadas deverão ser considerados para os procedimentos de recredenciamento.

- EAD para educação básica de jovens e adultos

- A matrícula em cursos a distância para educação básica de jovens e adultos poderá ser feita independentemente de escolarização anterior, obedecida a respectiva idade mínima e mediante avaliação do educando, que permita sua inscrição na etapa adequada, conforme regulamentação do respectivo sistema de ensino.

- A avaliação de desempenho dos estudantes deverá ser feita no processo, pela própria instituição de ensino credenciada para ministrar cursos a distância, segundo critérios e procedimentos previstos no projeto pedagógico do curso.

- As avaliações de que trata o caput e que conduzem à promoção, conclusão de estudos e à obtenção de diplomas ou certificados deverão ser especificadas no projeto pedagógico, de modo que o resultado final de exames presenciais predomine sobre o resultado das demais avaliações.

- A avaliação do desempenho do estudante para fins de promoção darse-á no processo, mediante o cumprimento das atividades programadas e a realização de exames presenciais periódicos sob a responsabilidade da instituição de ensino credenciada, segundo procedimentos e critérios definidos no projeto pedagógico do curso ou programa.

- Os resultados dos exames presenciais periódicos referidos no caput deste artigo prevalecerão sobre os demais resultados obtidos em quaisquer outras formas de avaliação a distância.

- Os estudantes de cursos de graduação a distância deverão ser

- inscritos pelas respectivas instituições de ensino nas avaliações nacionais correspondentes à sua área de diplomação.

- Diplomas de cursos realizados em instituições estrangeiras

- Os diplomas de cursos ou programas superiores de graduação a distância emitidos por instituição estrangeira, inclusive os ofertados 
em convênios com instituições sediadas no Brasil, deverão ser revalidados por universidade brasileira, conforme a legislação vigente.

- Para os fins de revalidação de diploma de curso ou programa de graduação, faculta-se à universidade exigir, do portador do diploma estrangeiro, que se submeta à complementação de estudos, provas ou exames destinados a suprir ou aferir conhecimentos, competências e habilidades na área de diplomação.

- Disposições Finais e Transitórias

- Os cursos a distância para a educação básica de jovens e adultos autorizados com duração inferior a dois anos no ensino fundamental e um ano e meio no ensino médio, deverão inscrever seus alunos em exames de certificação, para fins de conclusão do respectivo nível de ensino.

- Os exames citados no caput serão realizados pelo órgão executivo do respectivo sistema de ensino ou por instituições por ele credenciadas.

- Os Referenciais de Qualidade

Entre as tendências atuais em Educação, está a questão da busca da qualidade, em todas as etapas do trabalho desenvolvido pelas organizações educacionais, independentemente do nível de ensino, talvez por influência do que vem acontecendo o mundo corporativo, como exigência dos desafios da globalização. O que antes era uma intenção de dirigentes e professores, hoje é assumido como uma forma sistêmica de gestão, envolvendo todo processo sob a responsabilidade da organização. A definição de critérios de qualidade para dar a direção dos trabalhos depende de inúmeros fatores, alguns externos à própria organização educacional, mas não menos relevantes.

No caso da Educação a Distância no Brasil, o estabelecimento desses critérios ganha maior significação, quando se trata de ofertas de cursos por Instituições de Ensino Superior, que relutaram durante muitos anos em participar de sua realização como já foi apontado.

O Ministério da Educação estabeleceu Referenciais de Qualidade de EAD para a autorização de cursos de graduação a distância, buscando assegurar que as instituições trabalhem, continuamente, visando a melhorias na criação, aperfeiçoamento e divulgação de conhecimentos culturais, científicos, tecnológicos e profissionais, que contribuam para superar os problemas regionais, nacionais e internacionais e para o desenvolvimento sustentável dos seres humanos, sem exclusões, nas comunidades e ambientes em que vivem. E mais, objetiva orientar aos atores envolvidos - alunos, professores, técnicos e gestores de instituições de ensino superior - para que venham a usufruir de seus benefícios e empenhar-se por maior qualidade em seus processos e produtos.

Destaca a importância de que seja analisado cada item e que todos estejam articulados, numa abordagem global, para a construção e o bom desenvolvimento do 
projeto do curso. A realidade cultural e sócio-econômica da clientela, da cidade e região onde se situa a organização educacional, e suas particularidades precisam ser respeitadas e presentes na construção da proposta do curso. Tem como objetivo ainda orientar os atores do processo - alunos, professores, técnicos e gestores de instituições de ensino superior - que podem usufruir dessa forma de educação ainda pouco explorada no Brasil e empenhar-se por maior qualidade em seus processos e produtos.

O documento aponta, como base sobre a qual se fundamenta o trabalho, o "compromisso ético daquele que educa a distância é o de desenvolver um projeto humanizador, capaz de livrar o cidadão da massificação, mesmo quando dirigido a grandes contingentes".

Sem terem força de lei, a SEED/ Secretaria de Educação a Distância do MEC, indica dez itens básicos, que devem nortear as instituições que pretendem criar programas de graduação a distância, e que servirão, também, como orientação às Comissões de Especialistas ao analisarem os projetos. Os itens são:

1. compromisso dos gestores;

2. desenho do projeto;

3. equipe profissional multidisciplinar;

4. comunicação/interação entre os agentes;

5. recursos educacionais;

6. infra-estrutura de apoio;

7. avaliação contínua e abrangente;

8. convênios e parcerias;

9. transparência nas informações;

10. sustentabilidade financeira.

Considera, para efeito desses referenciais, a diferença básica entre educação presencial e a distância, sendo que na EAD o estudante constrói conhecimento, aprende e "desenvolve competências, habilidades, atitudes e hábitos relativos ao estudo, à profissão e à sua própria vida, no tempo e local que lhe são adequados, não com a ajuda em tempo integral da aula de um professor, mas com a mediação de professores (orientadores ou tutores), atuando ora a distância, ora em presença física ou virtual, e com o apoio de sistemas de gestão e operacionalização específicos, bem como de materiais didáticos intencionalmente organizados, apresentados em diferentes suportes de informação, utilizados isoladamente ou combinados, eveiculados através dos diversos meios de comunicação".

Destaca, ainda, que o foco está na aprendizagem do aluno e na superação da racionalidade tecnológica que valoriza meios em detrimento dos fins. O domínio das linguagens e das tecnologias ganha importância, sendo fundamental, no que ao serem considerados aspectos culturais, pedagógicos, operacionais, jurídicos, financeiros, de gestão e de formação dos profissionais envolvidos com a preparação e implementação desses cursos. 
Numa análise mais detalhada pode-se afirmar que os indicadores especificados para a EAD se assemelham aos que são exigidos para os cursos presenciais. Na verdade, demonstra a tendência de não discriminar cursos pela maior ou menor presença do estudante em classe, ou seja, a equidade por tanto tempo desejada entre as duas formas de disponibilizar a educação superior- presencialmente, a distância ou de forma conjugada e flexível. Destaca, portanto, a busca do padrão de qualidade, importante tanto para o cidadão quanto para a sociedade brasileira.

Quanto aos cursos de nível fundamental e médio, inclusive técnico, cabe aos Conselhos Estaduais de Educação, órgãos responsáveis por sua normatização, definir os indicadores a serem considerados, na construção das propostas dos cursos.

\section{PONTOS PARA REFLEXÃO}

Nas duas últimas décadas o Brasil apresenta-se como um espaço democrático de ofertas de $\mathrm{EAD}$, no que tange às tecnologias e suportes utilizados, e aos cursos que diferentes instituições vêm oferecendo, sejam instituições tradicionalmente educativas ou organizações que passam a assumir a responsabilidade de atualizar seus colaborados, utilizando o e-learning nas suas recém criadas universidades corporativas.

A maioria dos cursos de graduação a distância, por serem bastante recentes, ainda não apresentam dados de avaliação que possam vir a constituir-se em referencial para os que estão sendo criados e em andamento. O processo de avaliação desses cursos deve iniciar-se, no próximo ano, em uma ação conjunta proposta pelo Ministério. Até hoje as avaliações feitas foram muito mais para efeito de credenciamento de instituições e autorização e reconhecimento de cursos. Nesse contexto, vale destacar o conjunto de trabalhos acadêmicos de avaliação, que o Curso de Pedagogia da Universidade Federal de Mato Grosso já possui, e que merece uma análise mais profunda, por todos que estão começando agora sua incursão pela EAD.

Quanto à legislação, constata-se um avanço quanto ao credenciamento de cursos superiores, que passa a ser único, ou seja, sem distinção se a instituição se habilitou para oferecer presencialmente ou a distância, um curso de especialização, de graduação ou de pós- graduação stricto sensu., estando claro esse posicionando, na não identificação final nos diplomas concedidos pelos cursos.

No caso de instituições vinculadas aos Conselhos Estaduais (Educação Profissional de Nível Médio e Educação de J ovens e Adultos), passa a haver um credenciamento federal, quando a instituição pretender atuar para além de seu estado de origem, o que vai eliminar barreiras criadas por alguns conselhos de educação estaduais para expansão de cursos, independentemente da área geográfica onde esteja o aluno. 
Como já era anteriormente, o credenciamento deve vir acompanhado de um projeto de curso. No entanto, o credenciamento da instituição e a autorização do curso passam a ser, como o são, dois atos distintos.

Nesse contexto, as novas tecnologias abrem perspectivas para que cursos, com maior interatividade entre seus atores, possam chegar a segmentos da população localizadas em pontos distantes dos grandes centros.

Como as Instituições de Ensino Superior abriram-se, sem medo ou discriminação, para a EAD, acredita-se que a mesma qualidade dos cursos por elas oferecidos presencialmente venha a beneficiar um contingente até agora impossibilitado de ter acesso à universidade. Que abram o debate interno para a definição real dos critérios que serão considerado, sem a visão estreita apenas focada nos resultados da avaliação final da aprendizagem de seus estudantes. A EAD é um complexo de ações que se interligam e se sucedem no tempo e no espaço, com mediações tecnológicas que a realizam. Os indicadores devem considerar a especificidade desse tipo de oferta, os processos comunicacionais que se estabelecem entre os atores, as novas formas de construção de conhecimentos, os novos papéis e competências atribuídos a cada ator, ir fundo no que parece óbvio, como a leitura em novos suportes, a interatividade que se estabelece em novos modelos. A sinalização que já se apresenta é de não se ter mais distinção alguma entre educação presencial e a distância, incorporando cada uma delas as técnicas, tecnologias e metodologias mais adequadas ao momento histórico vivido, à clientela, a natureza do curso e aos recursos disponíveis, seja financeiro ou humano.

Já se conta com uma base legal - a Portaria 2.253/2001- que incentiva as instituições superiores brasileiras a um trabalho nessa direção.

Nossas crianças e jovens já são contemporâneos das tecnologias que ainda amedrontam alguns adultos. Eles terão pela frente uma uma sociedade em permanente desenvolvimento tecnológico, que vê e ouve o mundo que lhes chega "editado" e plugado, através dos muitos meios de informação e de comunicação. A comunicação se dará muitas vezes com os que estiverem conectados e navegando pelas infovias sem fronteiras, os novos desbravadores deste século que engatinha.

Que os indicadores de qualidade passem por revisões periódicas, à luz dos novos paradigmas de uma educação não bancária, uma Educação que busque a autonomia dos estudantes na construção de conhecimento por diferentes vias então abertas pelas tecnologias desse século, sem descuidar da formação humanística e do respeito à cultura de cada indivíduo e de seu país.

Porque, como afirmou Paulo Freire (Blois, 2005), "Não há nada parado. Tudo está sendo, nada é". 


\section{REFERENCIAS BIBLIOGRÁFICAS}

Blois, M.M., Ritto, A.C.A. (2001). E-learning, Universidades Corporativas e o Século XXI- A contribuição da Univir no Brasil. Madrid: Anais Virtual Educa.

Blois, M.M. (2000). Do Ensino por Correspondência à Internet - A Busca da De mocratização do Conhecimento. Miami: CREAD.

Blois, M.M. (2005). Reencontros com Paulo Freire e seus amigos. Niterói/BR: Fundação Euclides da Cunha-UFF.

Blois. M.M., Melca, F.M.A. (2003). Educação Corporativa - uma alternativa para a educação continuada. Rio de Janeiro: Revista DELFOS/UERJ, n.24, p.9-24, novembro de 2003.

Branco, A.C. (2003). A portaria no. 2253/2001 no contexto da evolução da educação à distância nas instituicões de ensino Superior do Brasil. IN: Silva, M (org).Educação online. São Paulo: Edições Loyola.

Castells, M. (1999). A sociedade em rede. São Paulo: PazeTerra.

Costa, A.C.A. (2002). A Educação Corporativa e a Gestão do Capital Intelectual [en línea]. Disponible en: http://www.edumax.com.br/] [consulta 2002, septiembre].

E-Learning News (2002). O Desenvolvimento das Universidades Corporativas [en línea]. Disponible en http://www.e learning-brasil.oom.br/[ [oonsulta 2002, diciembre].

Freire, Paulo. (1982). Pedagogia do Oprimido. São Paulo: Paze Terra.

Moran, J.M. Ensino e aprendizagem inovadoras com tecnologias audiovisuais e te lemáticas.In: Moran (org.) Novas tecnologias e mediação pedagógica. Campinas: Papirus.

Niskier, A. (1996). LDB - A nova Lei deEducação - Tudo sobre a Lei de Diretrizes e Bases da Educação Nacional - Uma visão crítica. Rio de J aneiro: Consultor.

Ritto, A.C.A; Blois, M.M. (2000). Educação Corporativa: Instrumento para Evolução dos Negócios das Organizacõos. Conferência Comemorativa do 10 을 Aniversário do CREAD.Caracas: UMA.

Silvio, J. (2000). La Virtualización da la Universidad. Venezuela: Colección Respuestas ediciones IESALC/ UNESCO.

\section{PALABRAS CLAVE}

Educação a Distância no Brasil, educação Superior a Distância no Brasil, regulamentação de Instituições de Ensino Superior, legislação de EAD, critérios de qualidade para EAD.

\section{KEY WORDS}

Distance Education in Brazil, higher Distance Education in Brazil, regulation of Institutions of Higher Education, current Legislation of EAD, quality' Indicators for EAD. 


\section{PERFIL ACADÉMICO DE LA AUTORA}

- Consultora de EAD- UNICARIOCA/ UNIVIR/ Universidade Virtual-Rio de J aneiro/RJ e Diretora de 1999-2004.

- Diretora do Escritório do CREAD/Brasil e Vice-Presidente do CREAD/Regional Brasil - 1996-2002.

- Livre Docência em Comunicação Social -Televisão e Rádio/Tese defendida: "Florescem as FM Educativas no Brasil" - 1996.

- Mestra em Tecnologia Educacional/Dissertação defendida: "Rádio Educativo no Brasil" - 1984.

- Autora do livro "Reencontros com Paulo Freire e seus amigos" (2005/ FEC-UFF) , de artigos científicos publicados em diversas revistas técnicas e de li-vros didáticos p/ o ensino fundamental

- Co-autora do livro "Educação Corporativa - Novas Tecnologias na Gestão do Conhecimento" (2005/ UNICARIOCA).

- Coordenadora da produção dos cursos interdisciplinares de especialização à distância (CD-Rom e Internet com momentos presenciais) para "Docentes de Educação Superior e Média" e de "Gestores de Organizações Educacionais" (360h/SENAC 2004/2005).

- Produtora e apresentadora de séries educativas para Rádio e para Tv

- Coordenadora de Projetos de Educação à Distância de âmbito nacional e produção de materiais para Ensino à Distância.

- Integrante de Comitês Científicos e participação em congressos nacionais e internacionais, na condição de conferencista e painelista.

- Pesquisadora nas áreas de Comunicação e de Educação a Distância.

Dirección postal:

Marlene Montezi Blois.

Rua Visconde de Pirajá, 128 apart. 1501.

Ipanema - Rio de J aneiro, Brasil.

CEP 22410-000

E-mail: m.blois@terra.com.br

mmblois@unicarioca.edu.br

Fecha recepción del artículo: 06. 02. 2006

Fecha aceptación del artículo: 16. 02. 2006 